\title{
Bone marrow aspirate concentrate versus platelet-rich plasma for treating knee osteoarthritis: a one-year non-randomized retrospective comparative study
}

\author{
Abed El-Hakim El-Kadiry ${ }^{1,2}$, Carlos Lumbao ${ }^{3}$, Natasha Salame ${ }^{2}$, Moutih Rafei ${ }^{4,5,6,7^{*}}$ and Riam Shammaa ${ }^{3,8^{*}}$
}

\begin{abstract}
Background: Knee osteoarthritis $(\mathrm{OA})$ is a debilitating condition affecting human body biomechanics and quality of life. Current standard care for knee OA leads to trivial improvement and entails multiple adverse effects or complications. Recently, investigational cell therapies injected intra-articularly, such as bone marrow aspirate concentrate (BMAC) and platelet-rich plasma (PRP), have shown safety and therapeutic potency providing patients with pain relief. In the current retrospective comparative study, we investigated the differences in pain and functional improvements in patients with symptomatic knee OA receiving intra-articular injections of BMAC vs PRP.
\end{abstract}

Methods: Pain and functionality scores were measured at baseline and at different time points post-injection over 12 months, using 3 self-administered, clinically validated questionnaires: the visual analogue scale (VAS) for assessing pain intensity, the knee injury and osteoarthritis outcome score (KOOS) for evaluating functionality and knee-related quality of life, and the Western Ontario and McMaster Universities Arthritis Index (WOMAC) for evaluating physical function. The repeated-measures general linear model with Sidak test for pairwise comparisons was used to investigate the influence of the treatment on the score evolution within groups (between baseline and each time point) and between groups (overall).

Results: The BMAC group ( $n=26$ knees) significantly improved in VAS, KOOS, and WOMAC scores between baseline and 12 months $(57.4,75.88$, and $73.95 \%$ mean score improvement, respectively). In contrast, the PRP group ( $n=13$ knees) witnessed nonsignificant improvement in all scores. BMAC, in comparison to PRP, induced significant improvement in outcomes by $29.38 \%$ on the VAS scale, $53.89 \%$ on the KOOS scale, and $51.71 \%$ on the WOMAC scale $(P<.002$, $P<.01, P<.011$, respectively).

Conclusions: Intra-articular autologous BMAC injections are safe, effective in treating pain, and ameliorate functionality in patients with symptomatic knee OA to a greater extent than PRP injections.

\footnotetext{
*Correspondence: moutih.rafei.1@umontreal.ca; riam.shammaa@utoronto.ca

${ }^{7}$ Department of Microbiology and Immunology, McGill University,

Montreal, QC, Canada

${ }^{8}$ Department of Family and Community Medicine, University of Toronto,

Toronto, ON, Canada

Full list of author information is available at the end of the article
}

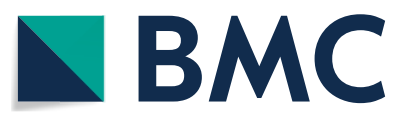

(c) The Author(s) 2021. Open Access This article is licensed under a Creative Commons Attribution 4.0 International License, which permits use, sharing, adaptation, distribution and reproduction in any medium or format, as long as you give appropriate credit to the original author(s) and the source, provide a link to the Creative Commons licence, and indicate if changes were made. The images or other third party material in this article are included in the article's Creative Commons licence, unless indicated otherwise in a credit line to the material. If material is not included in the article's Creative Commons licence and your intended use is not permitted by statutory regulation or exceeds the permitted use, you will need to obtain permission directly from the copyright holder. To view a copy of this licence, visit http://creativecommons.org/licenses/by/4.0/. The Creative Commons Public Domain Dedication waiver (http://creativeco mmons.org/publicdomain/zero/1.0/) applies to the data made available in this article, unless otherwise stated in a credit line to the data. 
Keywords: Knee, Osteoarthritis, Bone marrow aspirate concentrate, Platelet-rich plasma, Mesenchymal stromal cells, Visual analogue scale, Knee injury and osteoarthritis outcome score, Western Ontario and McMaster universities arthritis index

\section{Graphical abstract}

Intra-articular autologous BMAC therapy is safe and provides more relief to patients with symptomatic knee osteoarthritis compared to PRP therapy.

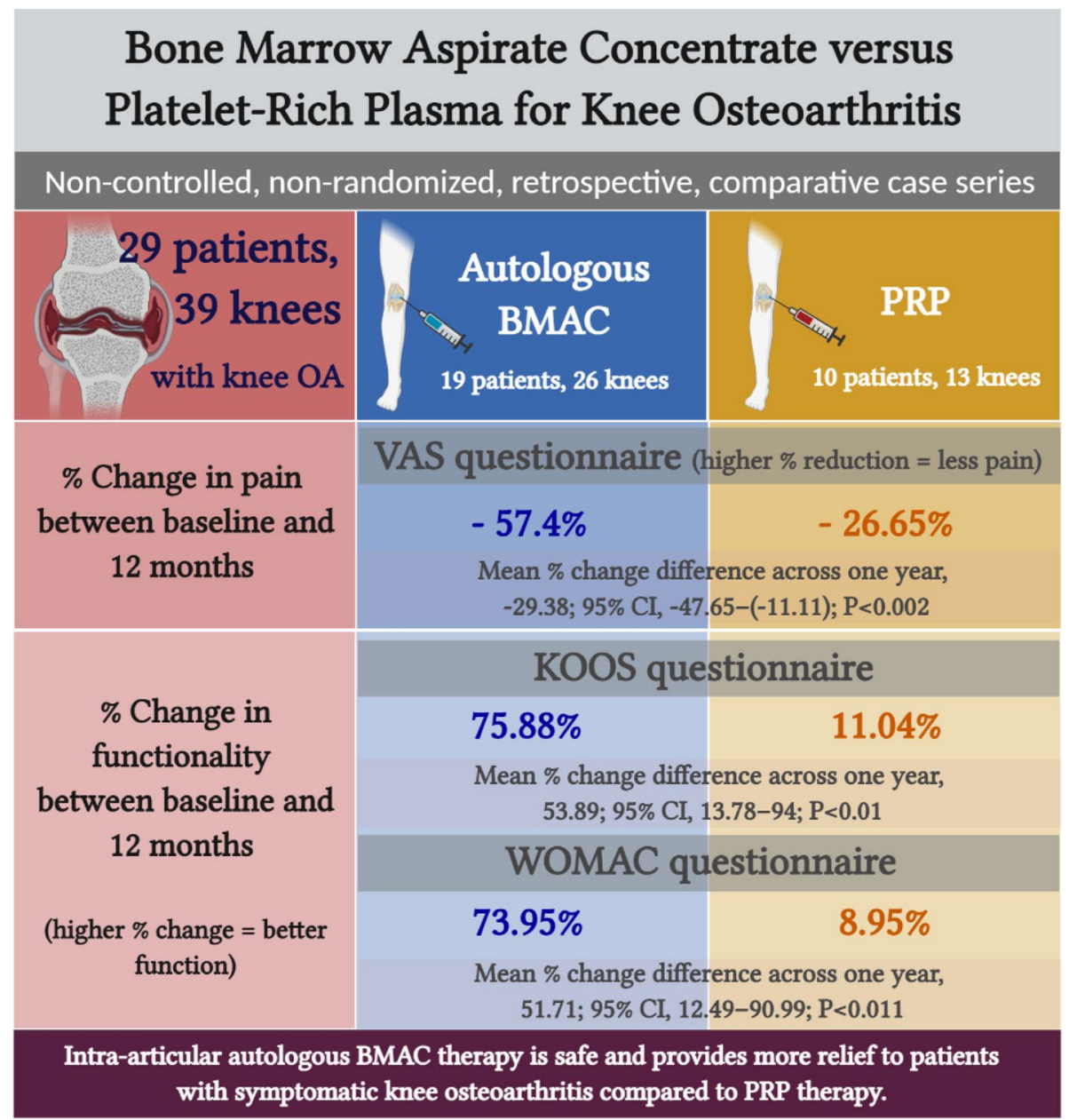

\section{Introduction}

Osteoarthritis (OA) is a degenerative joint disease impeding human body biomechanics and resulting in poor quality of life [1]. In Canada, 219,000 new cases were diagnosed with OA between 2016 and 2017 [2], with a sharp increase in OA patient numbers expected in the next 30 years [3]. OA of the knee is very frequent and results from the progressive degeneration of articular cartilage either idiopathically or following structural changes or trauma [4]. This causes joint pain and inflammation resulting in reduced joint range of motion (ROM) and mobility [5].
Standard care for knee OA includes conservative therapies or surgery [6]. Despite their affordability, management of pain, and/or delay of cartilage degeneration, conservative approaches like physiotherapy, analgesics, and intra-articular corticosteroid or hyaluronic acid (HA) injections have short-term efficacy and are still unproven to modify the disease [7]. Although surgery is recommended for end-stage knee OA, postoperative complications, cost, and lack of solid trial evidence remain problematic $[8,9]$. In addition to relieving symptoms, newer investigational intra-articular therapies including cell therapies modalities are proposed to 
reverse the underlying pathological processes of knee OA $[10,11]$.

Platelet-rich plasma (PRP) is an autologous blood component with high concentrations of platelets- megakaryocyte-derived fragments, whose secretome promotes cartilage repair in vitro and in vivo [12]. In clinical studies, PRP injections in symptomatic patients with knee OA have demonstrated safety and better pain and mobility outcomes up to 12 months after treatment [13]. However, further clinical data are imperative to strengthen the evidence of their efficacy [14].

Another attention-drawing cell therapy is bone marrow aspirate concentrate (BMAC) [15]. The advantage of this therapy is its composition of multiple cell fractions including platelets, monocytes, and mesenchymal stem cells (MSCs) - the latter notorious for their multi-lineage differentiation potential and secretome-mediated regenerative effects [16, 17]. Clinically, BMAC and MSCs have demonstrated a promising therapeutic potential in multiple orthopedic conditions [18], including spinal OA [19] and knee OA [10,17, 20]. However, the quality of clinical evidence corroborated by literature remains low $[15,21]$.

Backed by in vivo findings [22], few clinical studies have hitherto compared the functional and/or biological outcomes of PRP vs BMAC/MSC therapy in knee OA [23]. Therefrom, conflicting data have emerged mandating further investigations [24]. In this non-randomized comparative retrospective study, we sought to enhance available clinical knowledge by investigating potential differences in improvement on pain and functionality scales between PRP- and BMAC-treated patients. Outcomes were measured over 12 months at different time points using 3 self-administered, clinically validated questionnaires: i) the visual analogue scale (VAS) for assessing pain intensity on a scale of $0-10 \mathrm{~cm}$ [25-27], ii) the knee injury and osteoarthritis outcome score (KOOS) for evaluating symptoms, stiffness, pain, physical function (daily living and sports/recreational activities), and quality of life on a scale of $0-100(100=$ best function) $[28,29]$, and iii) the Western Ontario and McMaster Universities Arthritis Index (WOMAC) for evaluating symptoms, stiffness, pain, and daily function on a scale of $0-100(100=$ best function) [30-32].

\section{Materials and methods Study design and interventions}

The herein research was conducted according to the World Medical Association Declaration of Helsinki. Conforming with the local legislative and procedural institutional obligations concerning the retrospective study nature, ethical review and approval was not mandated, similar to our recent spinal OA research [19]. Informed consent forms as a written expression of patient voluntary participation were obtained. Patients also consented to the anonymous publishing of collected data. From a single center, 30 patients diagnosed with symptomatic knee OA and meeting the selection criteria (Table 1) were recruited between September 2016 and July 2018 after being referred by their primary care physicians. Diagnosis was confirmed based on history, physical examination, and diagnostic imaging using $\mathrm{X}$-rays with or without MRIs. All participants were well informed about the study objectives, associated risks and benefits, and treatment alternatives before and during the consent process. Patients received in their osteoarthritic knees either BMAC ( $n=27$ knees of 20 patients) or PRP ( $n=13$ knees of 10 patients) injections as delineated in the supplementary material (see Additional file 1: Tables 1-2).

\section{BMAC preparation}

As described elsewhere [17, 19], autologous bone marrow (BM) tissue was aspirated using a commercial trochar and concentrated for MSCs under sterile conditions. Briefly, the posterior superior iliac spine was marked with

Table 1 Selection criteria

\begin{tabular}{|c|c|}
\hline Inclusion criteria & Exclusion criteria \\
\hline 18 years of age or older & $\begin{array}{l}\text { Diagnosis of rheumatoid arthritis } \\
\text { or other lower extremities-affecting } \\
\text { musculoskeletal diseases }\end{array}$ \\
\hline Clinically and/or radiologically confirmed diagnosis of knee $O A(K L$ grade $1-4)$ in the past 6 months & Widespread pain \\
\hline Knee pain ( $\geq 2$ on VAS scale) lasting for 6 months or longer & Cancer \\
\hline \multirow[t]{4}{*}{ Willingness to discontinue analgesic medication for $48 \mathrm{~h}$ prior to each pain assessment } & Knee surgery in the previous 6 months \\
\hline & $\begin{array}{l}\text { Arthrocentesis or intra-articular } \\
\text { conservative therapy injections in the } \\
\text { last } 3 \text { months }\end{array}$ \\
\hline & History of stem cell knee injections \\
\hline & Inability to provide informed consent \\
\hline
\end{tabular}


ultrasound guidance for $\mathrm{BM}$ aspiration. Then $2 \%$ lidocaine was injected into the soft tissue and periosteum. An entry point was created using the introducer 14G trocar needle with which the bone was drilled through the periosteum and cortex and into the spongy bone. Using heparinized syringes, $1-6 \mathrm{cc}$ were subsequently aspirated per level while slowly withdrawing until approximately $60 \mathrm{cc}$ of aspirate was collected. BMAC was obtained and processed as described before for the mononuclear fraction containing MSCs $\left(\mathrm{CD} 45^{-} \mathrm{CD} 44^{+} \mathrm{CD} 90^{+} \mathrm{CD} 105^{+}\right)$among others [19].

\section{PRP preparation}

PRP tissue was processed using the Harvest Technologies SmartPrep Multicellular Processing System (Terumo BCT, Inc., Lakewood, CO). First, $30 \mathrm{cc}$ of blood was withdrawn from patients, anti-coagulated with acid citrate dextrose, and centrifuged for $14 \mathrm{~min}$. Three blood layers were then obtained and the upper two, the plasma and the buffy coat, collected to obtain the final PRP product.

\section{Injection protocol}

The injection site was prepared in sterile conditions using chlorhexidine swabs. Under ultrasound guidance, the area was visualized and marked, then PRP or BMAC injected into the appropriate knee intra-articularly. As seen in other studies $(20,33)$, knees were injected unilaterally or bilaterally. In case of unilateral knee OA, the knee was injected 1-3 times within a one-month period at maximum depending on the grade of OA. For bilateral knee OA, both knees were injected simultaneously. The number and application of injections and the grade of OA are further detailed in the supplementary material per knee per patient per group (see Additional file 1: Tables 1-2).

\section{Baseline and follow-up measurements}

In the baseline visit, all patients provided their date of birth and gender; were clinically assessed for range of motion (ROM), effusions, swelling, and tenderness to palpation at the joint line; and self-reported their kneerelated pain and functionality using the three clinically validated questionnaires: the VAS, the KOOS, and the WOMAC. The first follow-up post-injection occurred after 2 weeks in the clinic. Subsequently, follow-up visits occurred at 1, 3, 6, 9, and 12 months and entailed clinical reassessments and remeasurements of knee-related pain and functionality scores as well as collection of treatment-emergent adverse events.

\section{Statistical methods}

Baseline demographic and patient disease history information were summarized for the sample stratified by the numbers of knees injected and type of injection and presented as mean with standard deviation (SD) or 95\% confidence interval $(\mathrm{CI})$; median with interquartile range (IQR); or count with percent (\%) according to the type and/or normality of variables. The Shapiro-Wilk test was used to verify the normality of data distribution. Knee groups were compared at baseline in all variables using Independent-Samples t-test, Mann-Whitney U test, ChiSquared test, or Independent-Samples Median test based on the variable type and normality or non-normality of distribution.

The repeated-measures general linear model (GLM) with Sidak test for pairwise comparisons was used to investigate the influence of the treatment on the evolution of all knee-related clinical scores within a group. As such, time was considered a within-subject variable. The primary variable of interest within a group was the effect of time and the difference of estimated marginal means.

The repeated-measures GLM with Sidak test for pairwise comparisons was used to compare the change in VAS, KOOS, and WOMAC scores between knee groups throughout the duration of the study. As such, time was considered a within-subject variable and treatment a between-subject factor. The primary variable of interest between both groups was the effect of the treatment and the difference of estimated marginal means.

Pearson or Spearman correlation (2-tailed) was performed to assess correlation effects based on the types of variables.

All statistical analyses were performed using SPSS version 20.0 (IBM Corp). For all tests, $P<0.05$ was considered significant.

\section{Results}

Baseline demographics and clinical characteristics

As seen in other studies [20,33], data analyzed per patient were from either unilaterally or bilaterally injected knees. A total of 40 osteoarthritic knees (belonging to 30 patients) that have received either injection (BMAC, $n=27$ vs PRP, $n=13$ ) were assessed. One knee belonging to one patient treated with BMAC was lost to follow-up and thus could not be included in the analysis due to lack of complete data. No other serious complications or adverse events were recorded. Except for WOMAC scores, baseline parameters were homogeneously distributed between both groups (Table 2).

\section{BMAC provides more clinical benefits than PRP in patients with knee $\mathrm{OA}$}

To compare the potency of both autologous treatments, BMAC- and PRP-treated patients were followed up on several parameters over 12 months following the procedure. A statistically significant improvement was 
Table 2 Baseline demographics and clinical comparisons

\begin{tabular}{|c|c|c|c|}
\hline Patient characteristics & $\operatorname{BMAC}(n=26)^{a}$ & $\operatorname{PRP}(n=13)^{\mathrm{a}}$ & $P$ value \\
\hline Age, mean (SD) & $58.46(17.75)$ & $53(16.67)$ & $.354^{\mathrm{b}}$ \\
\hline Female, n (\%) & $12(46.15)$ & $6(46.15)$ & $1.00^{c}$ \\
\hline Left knee injections, n (\%) & $11(42.3)$ & $6(46.2)$ & $.82^{c}$ \\
\hline \multirow[t]{4}{*}{ Degree of $O A, n(\%)$} & $1,8(30.8 \%)$ & $1,2(15.4 \%)$ & \multirow[t]{4}{*}{$.35^{c}$} \\
\hline & $2,8(30.8 \%)$ & $2,8(61.5 \%)$ & \\
\hline & $3,8(30.8 \%)$ & $3,3(23.1 \%)$ & \\
\hline & $4,2(4 \%)$ & $4,0(0 \%)$ & \\
\hline Number of treatments, median (IQR) & $3(1-3)$ & $1(1-3)$ & $.424^{d}$ \\
\hline Total volume injected (ml), median (IQR) & $24(15-43.75)$ & $8(6-17.5)$ & $.088^{d}$ \\
\hline \multicolumn{4}{|l|}{ Baseline knee-related clinical scores } \\
\hline $\begin{array}{l}\text { VAS, median (IQR) } \\
\text { Baseline }\end{array}$ & $6(5-8)$ & $4(3-7)$ & $.142^{\mathrm{e}}$ \\
\hline KOOS, median (IQR) & $44.5(32.5-70)$ & $67(51.5-68.5)$ & $.076^{\mathrm{e}}$ \\
\hline WOMAC, median (IQR) & $42.5(37-74)$ & $70(50-73)$ & $.023^{\mathrm{e}}$ \\
\hline \multicolumn{4}{|l|}{${ }^{\mathrm{a}}$ Knees treated and analyzed } \\
\hline \multicolumn{4}{|l|}{${ }^{\mathrm{b}}$ Independent-samples t-test } \\
\hline \multicolumn{4}{|l|}{${ }^{\circ}$ Chi-Square test (2-sided) } \\
\hline${ }^{\mathrm{d}}$ Independent-samples median test & & & \\
\hline${ }^{\mathrm{e}}$ Independent-samples Mann-Whitney $\mathrm{U}$ test & & & \\
\hline
\end{tabular}

observed in all clinical scores of BMAC-injected knees. More specifically, VAS scores improved by $57.4 \%$ on average, decreasing from $6.23( \pm 2.1)$ at baseline to 2.58 $( \pm 1.68)$ at 12 months $(P=.000)$ (Fig. 1$)$.

Similarly, KOOS scores improved by $75.88 \%$ on average, increasing from $48.23( \pm 19.42)$ at baseline to 72.85 $( \pm 16.2)$ at 12 months $(P=.002)$ (Fig. 2$)$.

Changes (\%) in KOOS scores from baseline are represented as mean $\pm 95 \%$ CI. A general linear model for repeated measures was used to calculate $p$-values within each group compared to baseline and between treatment groups. BMAC, bone marrow aspirate concentrate; CI, confidence interval; ns, nonsignificant; PRP, platelet-rich plasma; Ref, reference.

WOMAC scores also showed a significant $73.95 \%$ improvement on average, increasing from $50.38( \pm 19.99)$ at baseline to $75.12( \pm 16.87)$ at 12 months $(P=.005)$ (Fig. 3).

On the other hand, no significant overall improvement was documented in any of the clinical scores assessed for PRP-injected knees. VAS scores fluctuated between baseline and 3 months around $5( \pm 2.35)$, then decreased significantly at 6 months by $27.55 \%(P=.002)$ and at 9 months by $33.3 \%(P=.012)$. At 12 months, however, VAS scores decreased to $3.85( \pm 2.76)$ albeit without attaining a significant difference compared to baseline (Fig. 1). KOOS scores also recorded a nonsignificant improvement between baseline $(61.69 \pm 11.51)$ and 12 months (67.62 \pm 12.38$)$ (Fig. 2). Similarly, a nonsignificant improvement in WOMAC scores was reported between baseline $(65.15 \pm 13.64)$ and 12 months (70 \pm 13.11$)$ (Fig. 3). Intergroup analysis showed significant differences between BMAC and PRP treatments in all adopted clinical scores, with mean improvements across all follow-up measurements being significantly higher in the BMAC group (Figs 1, 2, 3). Noteworthy, baseline WOMAC scores between both groups were significantly different, which could have biased the time-dependent intergroup statistical differences in this scale. Overall, these data show that BMAC treatment provides more clinical benefits to knee OA patients compared to PRP therapy.

\section{BMAC-induced improvements rely on distinct factors}

In the BMAC group, improvement in all scores correlated with patients' gender, with female patients exhibiting better responses than their male counterparts. Furthermore, improvement in VAS scores was dose-dependent, meaning that the greater the number of treatments and BMAC volume, the better the pain score. Both KOOS and WOMAC scores were further age- and OA degree-dependent. This implies that improved functionality correlates positively with younger patients exhibiting milder OA symptoms (Fig. 4 and Table 3). In PRP-treated patients, improvements in all scores were highly dependent on the volume of injected PRP. Furthermore, improvement in 


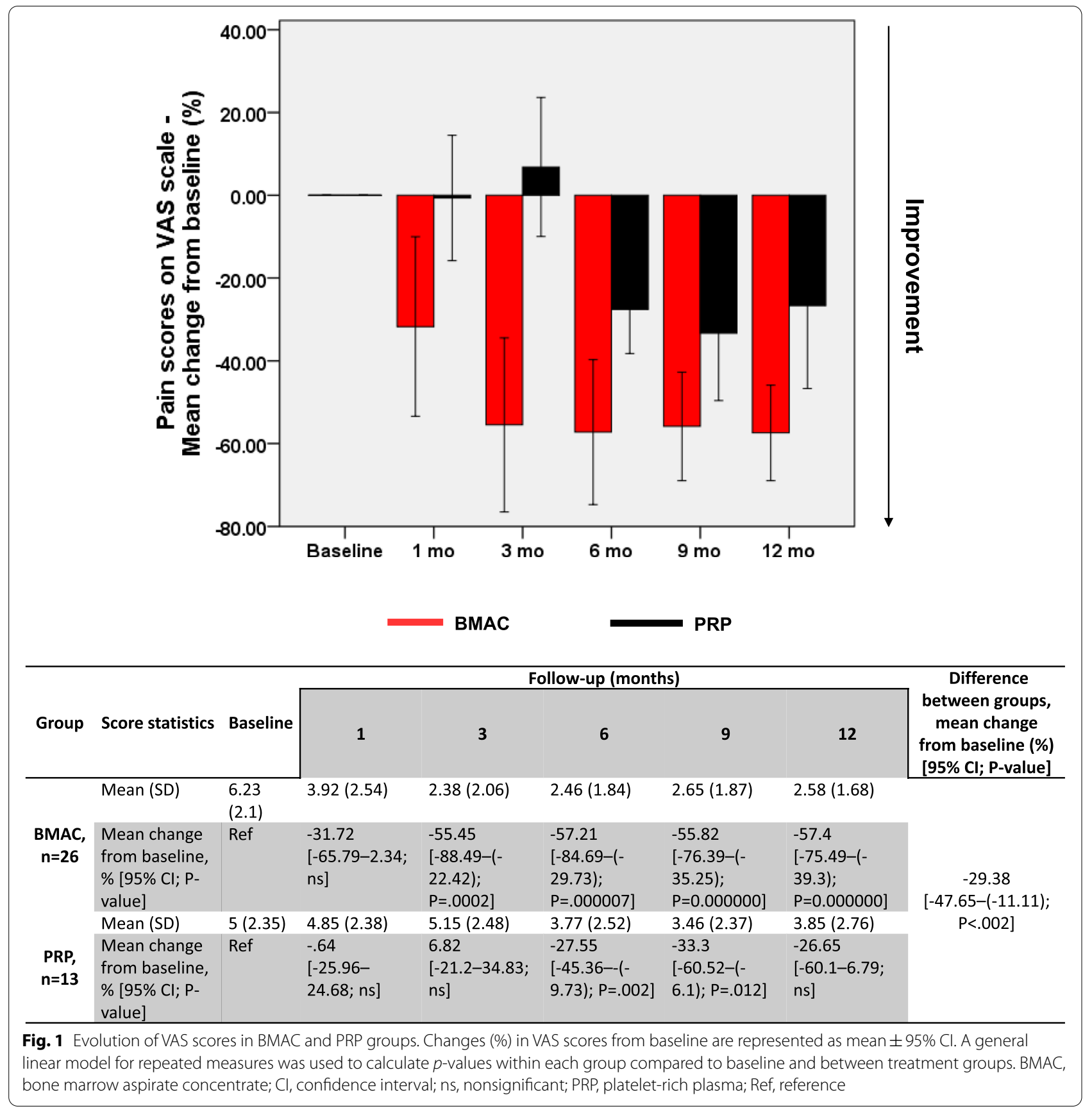

VAS scores was positively correlated with male patients and was dose-dependent (Table 3).

\section{BMAC is more beneficial than PRP especially in milder OA grades}

In subgroup analysis, we categorized patients into milder (grades 1-2) and more severe (grades 3-4) OA groups to further evaluate the effect of OA grades on clinical outcomes. The distribution of OA grades 1-2 vs grades
3-4 was homogeneous within treatment groups and between treatment groups (see Additional file 1: Table 3). Within treatment groups, no significant differences were recorded between OA grades 1-2 vs grades 3-4 in the improvement at 12 months in any of the 3 clinical scores (see Additional file 1: Fig. 1). Between treatment groups, however, significant differences were observed over 12 months in all adopted clinical scores only in patients with KL grades 1-2 (Fig. 5). Overall, our data show that 


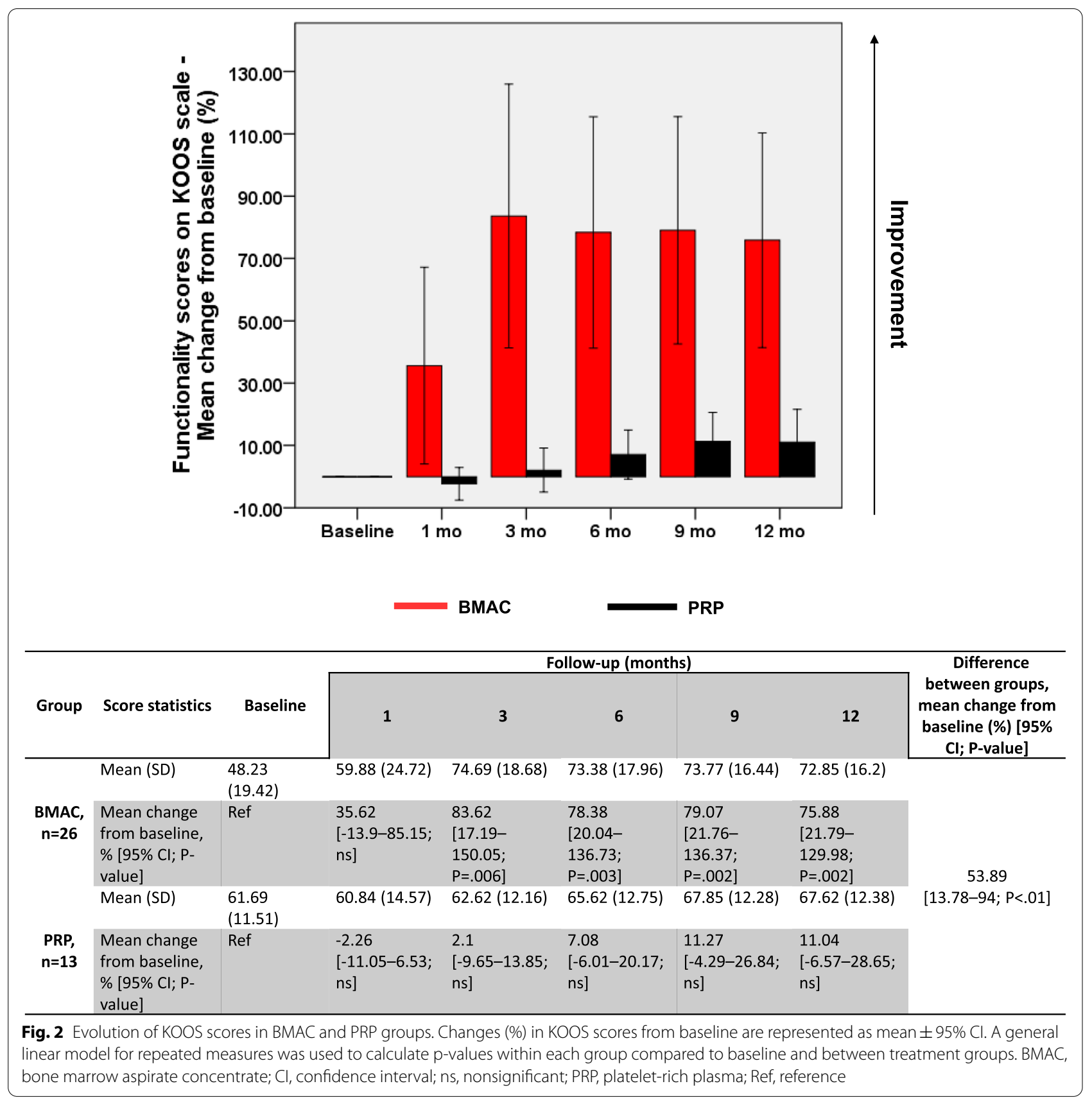

BMAC treatment could be more beneficial than PRP in patients with knee OA, especially with milder disease grades.

\section{Discussion}

Current knee OA treatment options, such as analgesics, corticosteroid injections, HA injections, and surgery, focus on managing joint pain and inflammation, yet their safety and long-term efficacy are still questioned $[6-9,34]$. To bypass these issues, recent investigational studies have adopted regenerative medicine products with the rationale of treating OA pathology by impacting the knee joint homeostasis [10, 11, 23, 35]. PRP, a platelet- and growth factor-studded therapy, has gained considerable attention in clinical settings, demonstrating 1-year long benefits, especially in younger patients with mild knee OA [36, 37]. The therapeutic outcomes of PRP could be linked to platelet- or non-plateletderived growth factors, such as insulin-like growth factor 1 (IGF-1) and platelet-derived growth factor 


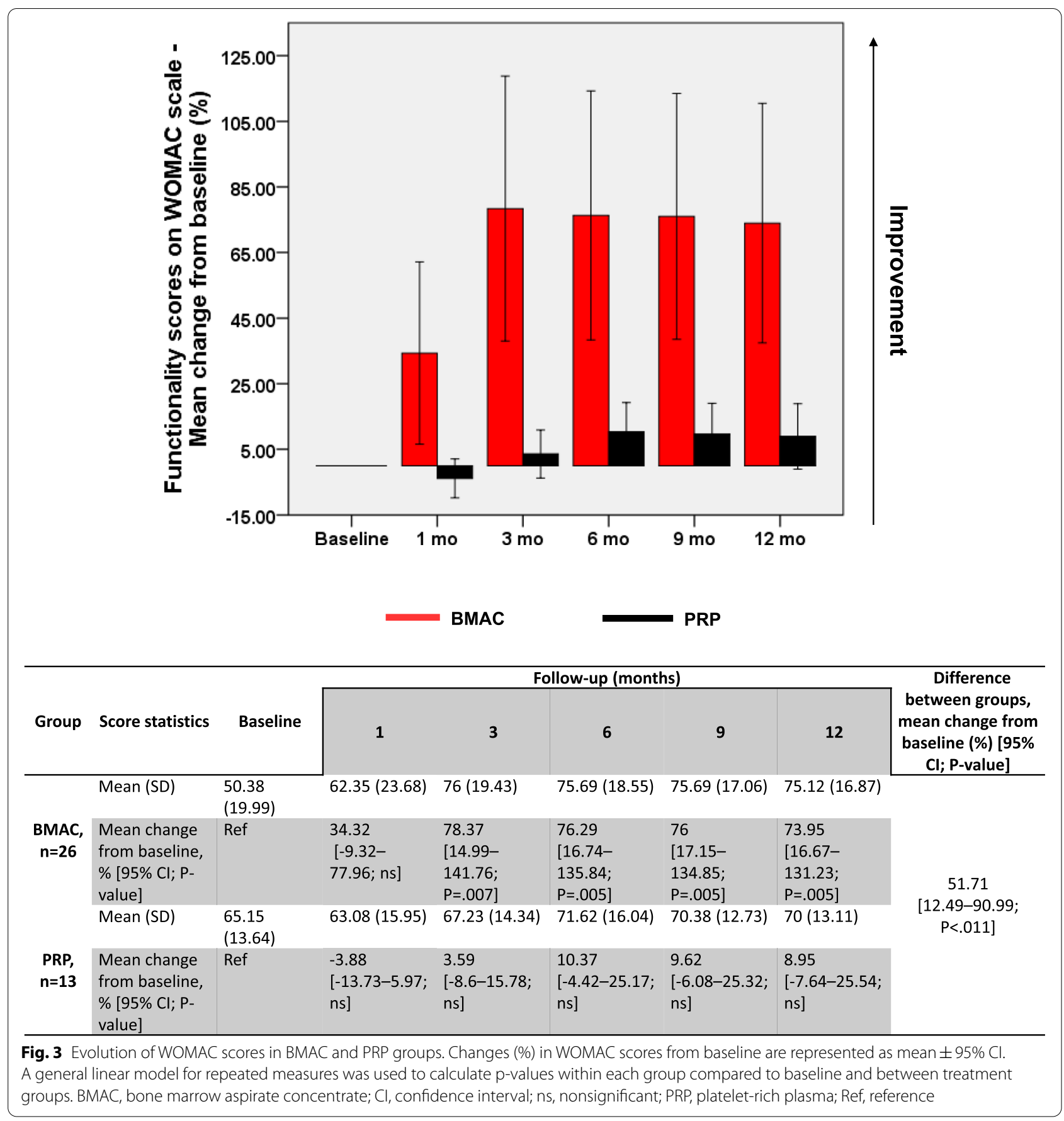

(PDGF), which induce anabolic and structural changes at the level of the articular extracellular matrix and stem cell niche, and may attenuate degenerative proinflammatory processes [38]. Recently, a meta-analysis of 18 randomized controlled trials (RCTs) of knee OA has shown that PRP elicits better improvement in pain and functionality scores compared to HA [39]. Contrarily, another meta-analysis of 43 RCTs revealed no differences between PRP and HA in terms of ameliorating pain and functionality [40]. Considering these contradictory reports, evidence for PRP's therapeutic superiority remains inconclusive. BMAC, on the other hand, harbors potent regenerative potential owing to its richness in platelets, white blood cells, and MSCs [12] that are characterized by their multi-lineage differentiation potential, anti-inflammatory profile, and 

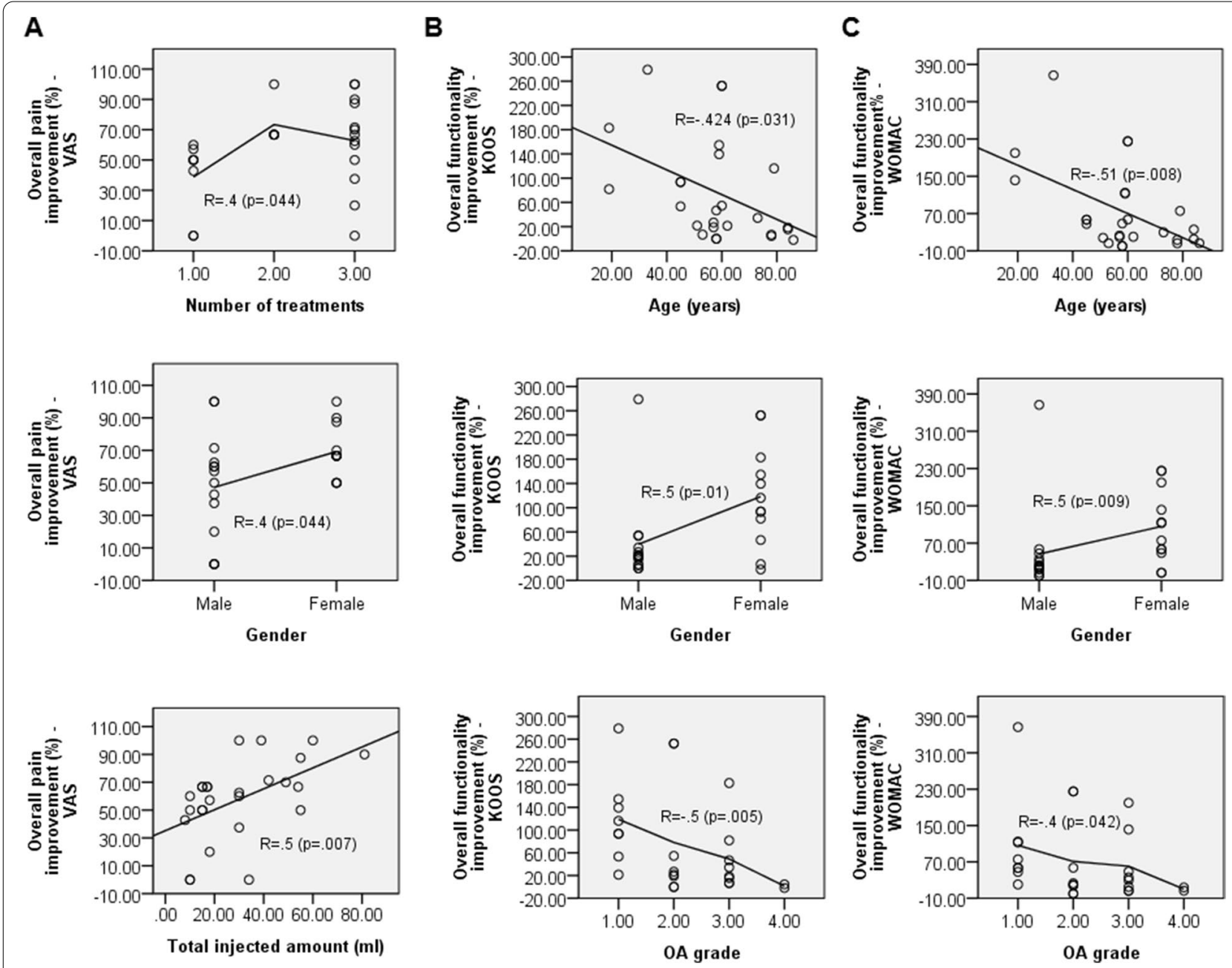

Fig. 4 Factors correlated with score improvements following BMAC injection. Scatter plots with fit or interpolation lines displaying overall improvement (\%) of BMAC-injected knees ( $n=26)$ at 12 months under $(\mathbf{A})$ VAS scores as a function of number of treatments received, gender, and total injected amount ( $\mathrm{ml}$ ) and (B) KOOS and (C) WOMAC scores as a function of age (years), gender, and baseline OA grade. R, Pearson's or Spearman's correlation coefficient

pro-angiogenic auxiliary effects [16]. However, it remains unclear whether PRP and BMAC/MSCs lead to comparable outcomes in knee OA [23]. This knowledge gap formed therefore the basis of the herein investigation.

Although head-to-head comparisons with the literature are difficult to perform due to the relatively small number of studies investigating BMAC as a monotherapy in knee OA and the vast differences in study designs and measured outcomes [41], our results are generally in line with previous findings showing that BMAC significantly improves VAS [20,33, 42], KOOS [20,33], and WOMAC scores [43]. Notable, the statistical difference in WOMAC scores between both groups could have been biased due to the imbalance reported at baseline.
The observed improvements correlated with several factors. More specifically, female patients receiving 2-3 treatments with higher volumes were more likely to improve on the pain scale compared to male patients receiving single treatments. Correlation data are also in line with previous studies demonstrating that the female gender, younger age groups, higher dose cellularity, and milder OA all have better prognosis [20, 33, 44-46]. In explanation of these correlated factors, increasing age was shown to be associated with reduced MSC numbers, lifespan, and proliferation/differentiation capacity [47-49]. In addition, human female MSCs were observed to divide more rapidly, exist in higher amounts in cell preparations, and promote a stronger anti-inflammatory environment by suppressing $\mathrm{T}$-cell proliferation 
Table 3 Factors correlated with the improvement in clinical scores in BMAC and PRP groups

\begin{tabular}{|c|c|c|c|c|c|c|}
\hline \multirow[t]{2}{*}{ Group } & \multirow[t]{2}{*}{ Improved outcomes } & \multicolumn{5}{|l|}{ Correlated factors } \\
\hline & & Gender & Age & OA grade & $\begin{array}{l}\text { Ascending } \\
\text { number of } \\
\text { treatments }\end{array}$ & $\begin{array}{l}\text { Ascending } \\
\text { injected } \\
\text { amounts }\end{array}$ \\
\hline \multirow[t]{3}{*}{$B M A C, n=26$} & VAS & Males $<$ Females; $\mathrm{R}=.4(p=.044)$ & ns & ns & $\mathrm{R}=.4(p=.044)$ & $\mathrm{R}=.5(p=.007)$ \\
\hline & KoOs & Males $<$ Females; $R=.5(p=.01)$ & $\begin{array}{l}\text { Younger>Older; } \\
\mathrm{R}=-.42 \\
(p=.031)\end{array}$ & $\begin{array}{l}\text { Better } \\
\text { grade }>\text { Worse } \\
\text { grade; } R=-.5 \\
(p=.005)\end{array}$ & ns & ns \\
\hline & WOMAC & Males $<$ Females; $\mathrm{R}=.5(p=.009)$ & $\begin{array}{l}\text { Younger>Older; } \\
\mathrm{R}=-.51 \\
(p=.008)\end{array}$ & $\begin{array}{l}\text { Better } \\
\text { grade }>\text { Worse } \\
\text { grade; } R=-.4 \\
(p=.042)\end{array}$ & ns & ns \\
\hline \multirow[t]{3}{*}{ PRP, $n=13$} & VAS & Males $>$ Females; $R=.61(p=.027)$ & ns & ns & $\mathrm{R}=.62(p=.025)$ & $R=.67(p=.012)$ \\
\hline & kOOS & ns & ns & ns & ns & $R=.77(p=.002)$ \\
\hline & WOMAC & ns & ns & ns & ns & $R=.73(p=.005)$ \\
\hline
\end{tabular}

$R$ Pearson's or Spearman's correlation coefficient, $n s$ Nonsignificant correlation

[50]. In terms of safety, although no BMAC-emergent adverse events were recorded, it is important to note the potential risks associated with bone marrow aspiration, including anemia, postoperative pain, neuralgia, and minor complications [51].

Although PRP-treated knees $(n=13)$ showed no statistically significant improvement on the scales of pain and functionality, the discrepancy between our results and previous data demonstrating remarkable clinical benefits with PRP [52-55] could be linked to our relatively small sample size preventing the detection of statistically significant improvement compared to baseline.

A recent study has examined the biologic differences between BMAC and PRP, showing that both differ in the concentration of leukocytes, cytokines, and growth factors, but not platelets, which might indicate potential therapeutic differences in orthopedic conditions [56]. Still and all, the two comparative analyses between BMAC and PRP in the literature have shown equivalent efficacy between both therapies with up to 12-month follow-up [23, 43]. A RCT was also conducted to determine which treatment is more effective, without yet disclosing any results (NCT03825133) [57]. Another trial has compared PRP-enhanced MSCs vs PRP, without disseminating further data (NCT01985633) [58]. The combined use of BMAC and PRP injected 1-to2-month apart has shown to provide benefits in retrospective case series; however, the proof of synergism is unclear
$[59,60]$. In our study, we show that BMAC therapy results in more significant improvements in knee pain and functionality than PRP throughout 12 months of follow-up (Graphical abstract). The weight of these improvements is concentrated in milder knee OA subgroups (knee OA grades 1-2) (Fig. 5). Further follow-up is also expected to support these outcomes. Noteworthy, it is pivotal to highlight the small sample size of the PRP group as well as the fact that current protocols have no consensus in terms of the used methodology, including the preparation, dosage, and administration of PRP and BMAC, which could weaken the quality of data and pose a challenge for comparative analyses $[18,41]$. Indeed, the differences in treatment protocols (ie, number of injections and volume injected) for each group, albeit balanced at baseline, could have impacted the quality of our intergroup outcomes. More homogenized treatment protocols are thus necessary to strengthen the evidence of intergroup differences. Additionally, another confounding factor potentially affecting intergroup differences is the effect of heparin used during BM aspiration. Recently, it has been shown that heparin impacts gene expression in BM-derived stromal cells without affecting their multilineage differentiation potential [61].

Overall, our results corroborate the therapeutic benefits of BMAC in patients with symptomatic knee OA (Graphical abstract). Notable, our study limitations

(See figure on next page.)

Fig. 5 Evolution of clinical scores in patients with KL grades $1-2$ between BMAC $(n=16)$ vs PRP groups $(n=10)$. Changes $(\%)$ in $(\mathbf{A})$ VAS scores, (B) KOOS scores, and (C) WOMAC scores from baseline are represented as mean $\pm 95 \% \mathrm{CI}$. Mean \% change differences between treatment groups across 1 year are provided as mean change from baseline (\%) [95\% Cl; $P$-value]. A significant difference was recorded in the mean change from baseline (\%) in all scores. A general linear model for repeated measures was used to calculate p-values between treatment groups. BMAC, bone marrow aspirate concentrate; $\mathrm{Cl}$, confidence interval; PRP, platelet-rich plasma 
A

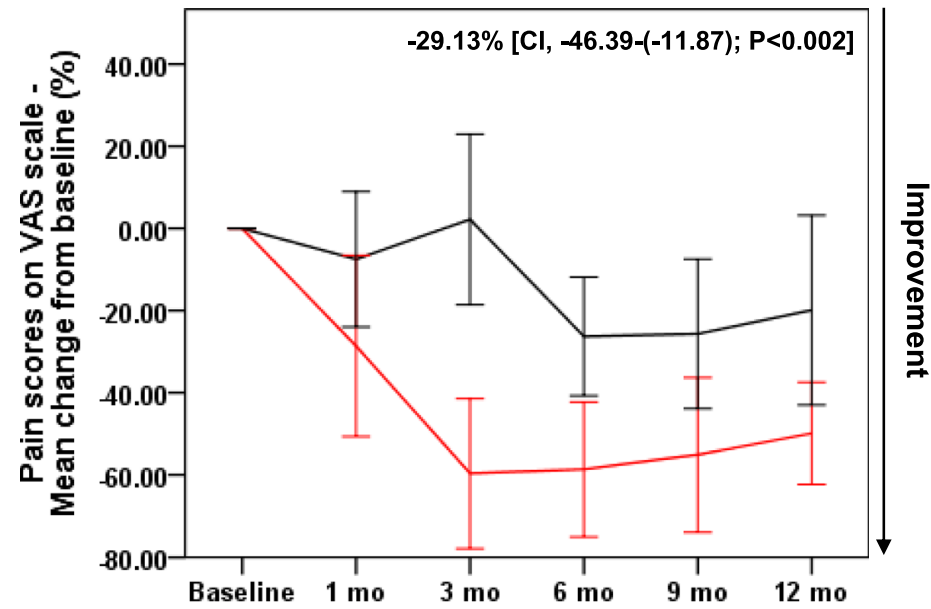

B

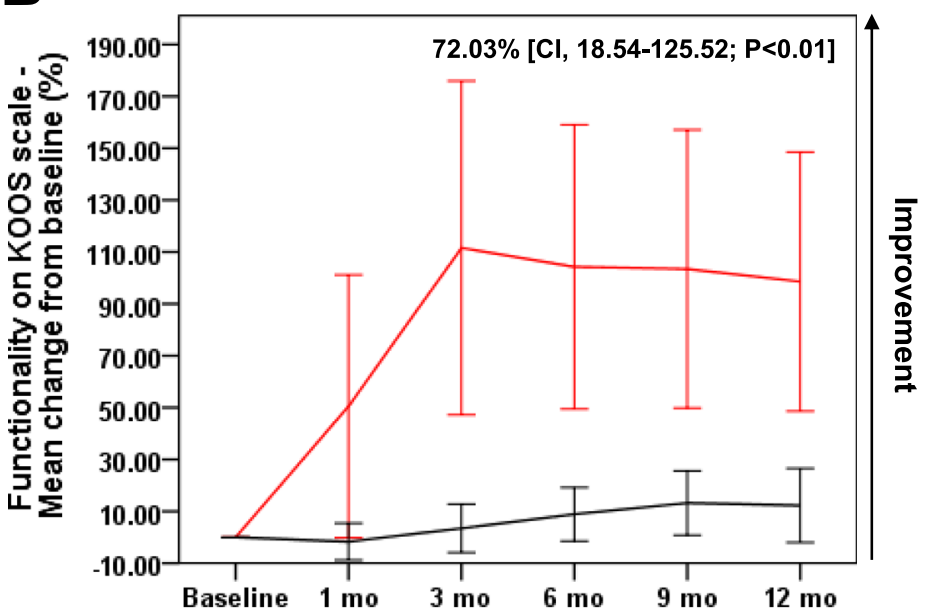

C

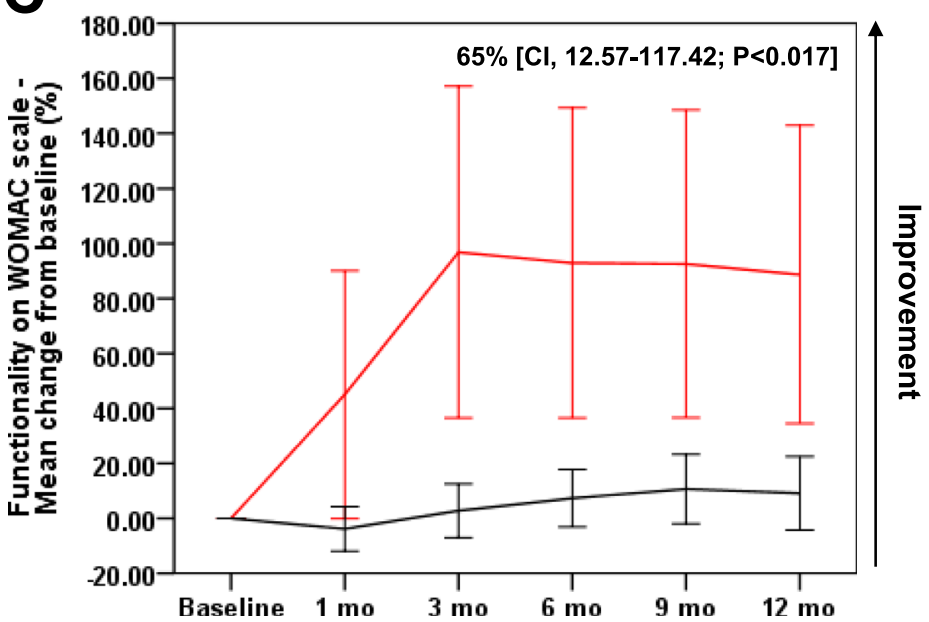

Fig. 5 (See legend on previous page.)

BMAC

PRP 
remain its: i) small sample size, ii) differences in group sizes, iii) uncontrolled nature, and iv) lack of morphological evaluation of knee cartilages pre- and postoperatively. A larger RCT with more standardized operating procedures will thus be necessary to validate the efficacy of both investigated therapies and their equivalence or lack thereof. Whether higher numbers of treatments and treatment volumes or combined therapy could further improve clinical outcomes is also a potential future directive.

\section{Conclusion}

Intra-articular autologous BMAC therapy safely and effectively reduced pain and improved functionality in patients with symptomatic knee OA to a greater extent than PRP therapy.

\section{Abbreviations}

BM: Bone marrow; BMAC: Bone marrow aspirate concentrate; $\mathrm{Cl}$ : Confidence interval; GLM: General linear model; HA: Hyaluronic acid; IQR: Interquartile range; MSC(s): Mesenchymal stem cell(s); OA: Osteoarthritis; PRP: Plateletrich plasma; RCTs: Randomized controlled trials; ROM: Range of motion; SD: Standard deviation.

\section{Supplementary Information}

The online version contains supplementary material available at https://doi. org/10.1186/s12891-021-04910-5.

Additional file 1 BMAC and PRP treatment modalities and OA gradebased distribution and sub-analyses. Table $\mathbf{1}$ and Table $\mathbf{2}$ demonstrate the data of both treatment modalities, BMAC and PRP, including patient ID, knees injected, knee OA grade, number of treatments received, and the volume injected per treatment. Table 3 demonstrates the distribution analyses of OA grades 1-2 vs OA grades 3-4 within treatment groups and between treatment groups. Figure 1 compares the improvement in clinical scores at 12 months between patients with OA grades 1-2 vs OA grades 3-4 within each treatment group.

\section{Acknowledgments}

We thank Esteena Javier (CCRT) and Jean-Pierre Bikorimana (from Université de Montréal) for their insightful criticism and review of the manuscript.

\section{Authors' contributions}

AE-K analyzed the data and wrote the first draft of the manuscript. CL managed the logistics of the study and participated in the treatment procedures. NS participated in data analyses and review. MR conceived the study, analyzed data, and edited the manuscript. RS conceived and conducted the studies, analyzed the data, and edited the manuscript. All authors contributed to the revision of the manuscript.

\section{Funding}

This work was entirely funded by the Canadian Centres for Regenerative Therapy (CCRT) (1027401-032017). MR holds a Fonds de la Recherche en Santé du Québec Junior I and II Awards.

\section{Availability of data and materials}

The datasets supporting the conclusions of this article are included within the article and its additional file.

\section{Declarations}

\section{Ethics approval and consent to participate}

This retrospective comparative study involving human participants was conducted according to the World Medical Association Declaration of Helsinki. Conforming with the local legislative and procedural institutional obligations at the Canadian Centres for Regenerative Therapy (CCRT, Toronto ON) concerning the study nature, ethical review and approval by the institutional ethics committee was not mandated. Informed consent forms as a written expression of patient voluntary participation were obtained. Patients also consented in writing to the anonymous publishing of collected data.

\section{Consent for publication \\ Not applicable.}

\section{Competing interests}

The authors declare that they have no competing interests.

\section{Author details}

${ }^{1}$ Laboratory of Thrombosis and Hemostasis, Montreal Heart Institute, Research Center, Montreal, QC, Canada. ${ }^{2}$ Department of Biomedical Sciences, Université de Montréal, Montreal, QC, Canada. ${ }^{3}$ Canadian Centres for Regenerative Therapy, Toronto, ON, Canada. ${ }^{4}$ Department of Pharmacology and Physiology, Université de Montréal, Montreal, QC, Canada. ${ }^{5}$ Department of Microbiology, Infectious Diseases and Immunology, Université de Montréal, Montreal, QC, Canada. ${ }^{6}$ Molecular Biology Program, Université de Montréal, Montreal, QC, Canada. ${ }^{7}$ Department of Microbiology and Immunology, McGill University, Montreal, QC, Canada. ${ }^{8}$ Department of Family and Community Medicine, University of Toronto, Toronto, ON, Canada.

Received: 11 July 2021 Accepted: 22 November 2021

Published online: 03 January 2022

\section{References}

1. Storheim K, Zwart JA. Musculoskeletal disorders and the global burden of disease study. Ann Rheum Dis. 2014;73:949-50.

2. Public Health Agency of Canada. Osteoarthritis in Canada. 2020. https:// www.canada.ca/en/public-health/services/publications/diseases-condi tions/osteoarthritis.html. Accessed 5 Jan 2021.

3. Davis A, Badley E, Mcglasson R, Alleyne Bsc J. Reducing the impact of OA: a report on the prevention and effective management in Canada. 2014. http://boneandjointcanada.com/wp-content/uploads/2014/05/BJC-OAMeeting-Report-Final.pdf. Accessed 5 Jan 2021.

4. Manlapaz DG, Sole G, Jayakaran P, Chapple CM. Risk factors for falls in adults with knee osteoarthritis: a systematic review. PM R. 2019;11:745-57.

5. Martel-Pelletier J, Maheu E, Pelletier JP, Alekseeva L, Mkinsi O, Branco J, et al. A new decision tree for diagnosis of osteoarthritis in primary care: international consensus of experts. Aging Clin Exp Res. 2019;31:19-30. https://doi.org/10.1007/s40520-018-1077-8.

6. McAlindon TE, Bannuru RR, Sullivan MC, Arden NK, Berenbaum F, BiermaZeinstra SM, et al. OARSI guidelines for the non-surgical management of knee osteoarthritis. Osteoarthr Cartil. 2014;22:363-88.

7. Wehling P, Moser C, Maixner W. How does surgery compare with advanced intra-articular therapies in knee osteoarthritis: current thoughts. Ther Adv Musculoskelet Dis. 2016;8:72-85. https://doi.org/10. 1177/1759720X16642405.

8. Lohmander LS, Roos EM. The evidence base for orthopaedics and sports medicine. BMJ. 2015;350:g7835. https://doi.org/10.1136/bmj.g7835.

9. Wartolowska K, Judge A, Hopewell S, Collins GS, Dean BJF, Rombach I, et al. Use of placebo controls in the evaluation of surgery: systematic review. BMJ. 2014;348:g3253. https://doi.org/10.1136/bmj.g3253.

10. Jo CH, Lee YG, Shin WH, Kim H, Chai JW, Jeong EC, et al. Intra-articular injection of mesenchymal stem cells for the treatment of osteoarthritis of the knee: a proof-of-concept clinical trial. Stem Cells. 2014;32:1254-66. https://doi.org/10.1002/stem.1634. 
11. Jayabalan P, Hagerty S, Cortazzo MH. The use of platelet-rich plasma for the treatment of osteoarthritis. Phys Sportsmed. 2014;42:53-62. https:// doi.org/10.3810/psm.2014.09.2076.

12. Fortier LA, Barker JU, Strauss EJ, McCarrel TM, Cole BJ. The role of growth factors in cartilage repair. Clin Orthop Relat Res. 2011;469:2706-15. https://doi.org/10.1007/s11999-011-1857-3.

13. Laudy ABM, Bakker EWP, Rekers M, Moen MH. Efficacy of platelet-rich plasma injections in osteoarthritis of the knee: a systematic review and meta-analysis. Br J Sports Med. 2015;49:657-72. https://doi.org/10.1136/ bjsports-2014-094036.

14. Cook CS, Smith PA. Clinical update: why PRP should be your first choice for injection therapy in treating osteoarthritis of the knee. Curr Rev Musculoskelet Med. 2018;11:583-92. https://doi.org/10.1007/ s12178-018-9524-X.

15. Kim GB, Seo MS, Park WT, Lee GW. Bone marrow aspirate concentrate: its uses in osteoarthritis. Int J Mol Sci. 2020;21:3224. https://doi.org/10.3390/ ijms21093224.

16. Shammaa R, El-Kadiry AE, Abusarah J, Rafei M. Mesenchymal stem cells beyond regenerative medicine. Front cell. Dev Biol. 2020;8:72. https://doi. org/10.3389/fcell.2020.00072.

17. Kouroupis D, Ahari AF, Correa D, Shammaa R. Intralesional injection of bone marrow aspirate concentrate for the treatment of osteonecrosis of the knee secondary to systemic lupus Erythematosus: a case report. Front Bioeng Biotechnol. 2020;8:202. https://doi.org/10.3389/fbioe.2020.00202.

18. Eder C, Schmidt-Bleek K, Geissler S, Sass FA, Maleitzke T, Pumberger M, et al. Mesenchymal stromal cell and bone marrow concentrate therapies for musculoskeletal indications: a concise review of current literature. Mol Biol Rep. 2020;47:4789-814. https://doi.org/10.1007/s11033-020-05428-0.

19. El Kadiry AEH, Lumbao C, Rafei M, Shammaa R. Autologous BMAC therapy improves spinal degenerative joint disease in lower back pain patients. Front Med. 2021:8:622573.

20. Do KJ, Lee GW, Jung GH, Kim CK, Kim T, Park JH, et al. Clinical outcome of autologous bone marrow aspirates concentrate (BMAC) injection in degenerative arthritis of the knee. Eur J Orthop Surg Traumatol. 2014:24:1505-11. https://doi.org/10.1007/s00590-013-1393-9.

21. Xia P, Wang X, Lin Q, Li X. Efficacy of mesenchymal stem cells injection for the management of knee osteoarthritis: a systematic review and meta-analysis. Int Orthop. 2015;39:2363-72. https://doi.org/10.1007/ s00264-015-2785-8.

22. Zhong W, Sumita Y, Ohba S, Kawasaki T, Nagai K, Ma G, et al. In vivo comparison of the bone regeneration capability of human bone marrow concentrates vs. platelet-rich plasma. PLoS One. 2012;7:e40833. https:// doi.org/10.1371/journal.pone.0040833.

23. Estrada E, Décima JL, Rodríguez M, Di Tomaso M, Roberti J. Patientreported outcomes after platelet-rich plasma, bone marrow aspirate, and adipose-derived mesenchymal stem cell injections for symptomatic knee osteoarthritis. Clin Med Insights Arthr Musculoskelet Disord. 2020;13:1179544120931086. https://doi.org/10.1177/1179544120931086.

24. Moatshe G, Morris ER, Cinque ME, Pascual-Garrido C, Chahla J, Engebretsen $L$, et al. Biological treatment of the knee with platelet-rich plasma or bone marrow aspirate concentrates: a review of the current status. Acta Orthop. 2017;88:670-4. https://doi.org/10.1080/17453674 2017.1368899.

25. Alghadir A, Anwer S, lqbal A, lqbal Z. Test-retest reliability, validity, and minimum detectable change of visual analog, numerical rating, and verbal rating scales for measurement of osteoarthritic knee pain. J Pain Res. 2018;2018:851-6. https://doi.org/10.2147/JPR.S158847.

26. Roach KE, Brown MD, Dunigan KM, Kusek Cl, Walas M. Test-retest reliability of patient reports of low Back pain. J Orthop Sport Phys Ther. 1997;26:253-9. https://doi.org/10.2519/jospt.1997.26.5.253.

27. Brokelman RBG, Haverkamp D, van Loon C, Hol A, van Kampen A, Veth R. The validation of the visual analogue scale for patient satisfaction after total hip arthroplasty. Eur Orthop Traumatol. 2012;3:101-5. https://doi. org/10.1007/s12570-012-0100-3.

28. Roos EM, Roos HP, Lohmander LS, Ekdahl C, Beynnon BD. Knee injury and osteoarthritis outcome score (KOOS) - development of a self-administered outcome measure. J Orthop Sports Phys Ther. 1998;28:88-96. https://doi.org/10.2519/jospt.1998.28.2.88.

29. Roos EM, Lohmander LS. The knee injury and osteoarthritis outcome score (KOOS): from joint injury to osteoarthritis. Health Qual Life Outcomes. 2003;1:64. https://doi.org/10.1186/1477-7525-1-64.
30. Bellamy N, Goldsmiti CH, Buchanan WW, Campbell J, Duku E. Prior score availability: observations using the WOMAC osteoarthritis index. Rheumatology. 1991;30:150-1. https://doi.org/10.1093/rheumatology/30.2.150.

31. Bellamy N, Buchanan W, Goldsmith C, Campbell J, Stitt L. Validation study of WOMAC: a health status instrument for measuring clinically important patient relevant outcomes to antirheumatic drug therapy in patients with osteoarthritis of the hip or knee. J Rheumatol. 1988;15:1833-40 https://pubmed.ncbi.nlm.nih.gov/3068365/. Accessed 7 Jan 2021.

32. Orthopaedic Scores. Knee Injury and Osteopaedic Outcome Score (WOMAC). https://www.orthopaedicscore.com/scorepages/knee_injury_ osteopaedic_outcome_score_womac.html. Accessed 28 Feb 2021.

33. Mautner K, Bowers R, Easley K, Fausel Z, Robinson R. Functional outcomes following microfragmented adipose tissue versus bone marrow aspirate concentrate injections for symptomatic knee osteoarthritis. Stem Cells Transl Med. 2019;8:1149-56. https://doi.org/10.1002/sctm.18-0285.

34. Gregori D, Giacovelli G, Minto C, Barbetta B, Gualtieri F, Azzolina D, et al. Association of pharmacological treatments with long-term pain control in patients with knee osteoarthritis: a systematic review and meta-analysis. JAMA - J Am Med Assoc. 2018;320:2564-79. https://doi.org/10.1001/ jama.2018.19319.

35. Themistocleous GS, Chloros GD, Kyrantzoulis IM, Georgokostas IA, Themistocleous MS, Papagelopoulos PJ, et al. Effectiveness of a single intra-articular bone marrow aspirate concentrate (BMAC) injection in patients with grade 3 and 4 knee osteoarthritis. Heliyon. 2018;4:e00871.

36. Chang KV, Hung CY, Aliwarga F, Wang TG, Han DS, Chen WS. Comparative effectiveness of platelet-rich plasma injections for treating knee joint cartilage degenerative pathology: a systematic review and meta-analysis. Arch Phys Med Rehabil. 2014;95:562-75.

37. Raeissadat SA, Rayegani SM, Hassanabadi H, Fathi M, Ghorbani E, Babaee $M$, et al. Knee osteoarthritis injection choices: platelet-rich plasma (PRP) versus hyaluronic acid (a one-year randomized clinical trial). Clin Med Insights Arthr Musculoskelet Disord. 2015;8:1-8.

38. Richards MM, Maxwell JS, Weng L, Angelos MG, Golzarian J. Intra-articular treatment of knee osteoarthritis: from anti-inflammatories to products of regenerative medicine. Phys Sportsmed. 2016;44:101-8. https://doi.org/ 10.1080/00913847.2016.1168272.

39. Belk JW, Kraeutler MJ, Houck DA, Goodrich JA, Dragoo JL, McCarty EC. Platelet-rich plasma versus hyaluronic acid for knee osteoarthritis: a systematic review and Meta-analysis of randomized controlled trials. Am J Sports Med. 2021;49:249-60. https://doi.org/10.1177/0363546520909397.

40. Han SB, Seo IW, Shin YS. Intra-articular injections of hyaluronic acid or steroids associated with better outcomes than platelet-rich plasma, adipose Mesenchymal stromal cells, or placebo in knee osteoarthritis: a network Meta-analysis. Arthrosc - J Arthrosc Relat Surg. 2021;37:292-306.

41. Cavallo C, Boffa A, Andriolo L, Silva S, Grigolo B, Zaffagnini S, et al. Bone marrow concentrate injections for the treatment of osteoarthritis: evidence from preclinical findings to the clinical application. Int Orthop. 2021;45:525-38. https://doi.org/10.1007/s00264-020-04703-w.

42. Shapiro SA, Kazmerchak SE, Heckman MG, Zubair AC, O'Connor MI. A prospective, single-blind, placebo-controlled trial of bone marrow aspirate concentrate for knee osteoarthritis. Am J Sports Med. 2017:45:82-90. https://doi.org/10.1177/0363546516662455.

43. Anz AW, Hubbard R, Rendos NK, Everts PA, Andrews JR, Hackel JG. Bone marrow aspirate concentrate is equivalent to platelet-rich plasma for the treatment of knee osteoarthritis at 1 year: a prospective, Randomized Trial. Orthop J Sport Med. 2020;8:2325967119900958. https://doi.org/10. $1177 / 2325967119900958$.

44. Centeno C, Pitts J, Al-Sayegh H, Freeman M. Efficacy of autologous bone marrow concentrate for knee osteoarthritis with and without adipose graft. Biomed Res Int. 2014;2014:1-9. https://doi.org/10.1155/2014/370621.

45. Koh YG, Jo SB, Kwon OR, Suh DS, Lee SW, Park SH, et al. Mesenchymal stem cell injections improve symptoms of knee osteoarthritis. Arthrosc - J Arthrosc Relat Surg. 2013;29:748-55.

46. Koh YG, Choi YJ. Infrapatellar fat pad-derived mesenchymal stem cell therapy for knee osteoarthritis. Knee. 2012;19:902-7.

47. Stenderup K, Justesen J, Clausen C, Kassem M. Aging is associated with decreased maximal life span and accelerated senescence of bone marrow stromal cells. Bone. 2003;33:919-26.

48. Muschler GF, Nitto H, Boehm CA, Easley KA. Age- and gender-related changes in the cellularity of human bone marrow and the prevalence of osteoblastic progenitors. J Orthop Res. 2001;19:117-25. 
49. Mendes SC, Tibbe JM, Veenhof M, Bakker K, Both S, Platenburg PP, et al. Bone tissue-engineered implants using human bone marrow stromal cells: effect of culture conditions and donor age. Tissue Eng. 2002;8:91120. https://doi.org/10.1089/107632702320934010.

50. Siegel G, Kluba T, Hermanutz-Klein U, Bieback K, Northoff H, Schäfer R. Phenotype, donor age and gender affect function of human bone marrow-derived mesenchymal stromal cells. BMC Med. 2013;11:146. https://doi.org/10.1186/1741-7015-11-146.

51. Hernigou P, Desroches A, Queinnec S, Flouzat Lachaniette CH, Poignard A, Allain J, et al. Morbidity of graft harvesting versus bone marrow aspiration in cell regenerative therapy. Int Orthop. 2014;38:1855-60. https://doi. org/10.1007/S00264-014-2318-X.

52. Filardo G, Di Matteo B, Di Martino A, Merli ML, Cenacchi A, Fornasari $P$, et al. Platelet-rich plasma intra-articular knee injections show no superiority versus viscosupplementation: a randomized controlled trial. Am J Sports Med. 2015;43:1575-82. https://doi.org/10.1177/0363546515 582027.

53. Patel S, Dhillon MS, Aggarwal S, Marwaha N, Jain A. Treatment with platelet-rich plasma is more effective than placebo for knee osteoarthritis: a prospective, double-blind, randomized trial. Am J Sports Med. 2013;41:356-64. https://doi.org/10.1177/0363546512471299.

54. Khoshbin A, Leroux T, Wasserstein D, Marks P, Theodoropoulos J, OgilvieHarris $D$, et al. The efficacy of platelet-rich plasma in the treatment of symptomatic knee osteoarthritis: a systematic review with quantitative synthesis. Arthrosc - J Arthrosc Relat Surg. 2013;29:2037-48. https://doi. org/10.1016/j.arthro.2013.09.006.

55. O'Connell B, Wragg NM, Wilson SL. The use of PRP injections in the management of knee osteoarthritis. Cell Tissue Res. 2019;376:143-52. https:// doi.org/10.1007/s00441-019-02996-X.

56. Cassano JM, Kennedy JG, Ross KA, Fraser EJ, Goodale MB, Fortier LA. Bone marrow concentrate and platelet-rich plasma differ in cell distribution and interleukin 1 receptor antagonist protein concentration. Knee Surg Sport Traumatol Arthrosc. 2018;26:333-42. https://doi.org/10.1007/ s00167-016-3981-9.

57. National Library of Medicine. The comparison of knee osteoarthritis treatment with bone marrow aspirate concentrate, leukocyte rich platelet rich plasma and hyaluronic acid. 2019. https://clinicaltrials.gov/ct2/show/ NCT03825133? cond=Osteo+Arthritis + Knee\&intr=BMAC\%2FPRP\& draw $=28$ rank=3. Accessed 6 Jan 2021.

58. National Library of Medicine. mesenchymal stem cells enhanced with PRP versus PRP in OA knee. 2013. https://clinicaltrials.gov/ct2/show/ NCT01985633. Accessed 6 Jan 2021.

59. Subaşı V, Ekiz T. Bone marrow aspiration concentrate and platelet-rich plasma in the treatment of knee osteoarthritis: a report of three cases. Complement Ther Clin Pract. 2019;34:113-5. https://doi.org/10.1016/j. ctcp.2018.11.005.

60. Sampson S, Smith J, Vincent H, Aufiero D, Zall M, Botto-Van-Bemden A. Intra-articular bone marrow concentrate injection protocol: short-term efficacy in osteoarthritis. Regen Med. 2016;11:511-20. https://doi.org/10. 2217/rme-2016-0081.

61. Laner-Plamberger S, Oeller M, Poupardin R, Krisch L, Hochmann S, Kalathur R, et al. Heparin differentially impacts gene expression of stromal cells from various tissues. Sci Rep. 2019;9:7258. https://doi.org/10.1038/ s41598-019-43700-x.

\section{Publisher's Note}

Springer Nature remains neutral with regard to jurisdictional claims in published maps and institutional affiliations.

Ready to submit your research? Choose BMC and benefit from:

- fast, convenient online submission

- thorough peer review by experienced researchers in your field

- rapid publication on acceptance

- support for research data, including large and complex data types

- gold Open Access which fosters wider collaboration and increased citations

- maximum visibility for your research: over $100 \mathrm{M}$ website views per year

At BMC, research is always in progress.

Learn more biomedcentral.com/submissions 